\title{
EmPower the Yukon. Using Community Renewable Energy in the Transition to Energy Resilience:A Social Enterprise Approach
}

\author{
Karen Furlong
}

\begin{abstract}
This article demonstrates how community renewable energy (RE) can lead the Yukon towards energy resilience. As shown in other areas of Canada and abroad, community RE delivery through social economy businesses can be a bridge between government programs and provision of renewable technologies to communities. Through identifying the opportunities and barriers in the Yukon, this study demonstrates that social enterprise delivery of community RE will create energy resilience in Yukon communities, while empowering their residents. From the themes of the role of the state, community connection,Yukon cultural influence, technical considerations, and social enterprise start-up, a framework emerged for social enterprise delivery of community RE in the Yukon. This implementation framework, entitled "EmPower the Yukon," is comprised of factors important for success and includes starting small, harnessing the power of government, finding community champions, working with community development corporations, and leading with both the heart and mind. The research has shown that empowering Yukoners to become involved in the transition to energy resilience is the best way to ensure successful social enterprise delivery of renewable energy projects.
\end{abstract}


The threat of climate change and its associated impacts are increasingly dominating news stories while scientific evidence is mounting that our world is changing. The impacts are particularly evident in the fragile northern parts of the globe, where small climatic changes are having dramatic effects. The North, a land of extremes dominated by snow, ice, and permafrost, can be harsh yet fragile, and is vulnerable to small climactic shifts. These shifts can have myriad impacts such as melting permafrost, reduced biocomplexity, disappearance of glaciers and sea ice, and introduction of invasive species (Hinzman et al., 2005). According to the World Wildlife Federation, "climate change is faster and more severe in the Arctic than in most of the rest of the world. The Arctic is warming at a rate of almost twice the global average" (World Wildlife Federation, 2018). In the land of the midnight sun, climate change is a spectre that warrants particular attention.

The Yukon, in northwestern Canada, is experiencing temperature rises at a faster rate than Canada as a whole (Office of the Auditor General of Canada, 2017). The increased risk of climate change impacts, combined with dependence on fossil fuels, creates an economic disadvantage and introduces vulnerability to supply disruptions as well as cost volatilities (A Northern Vision, 2016). A bleak message, to be sure, but there is good news in the form of renewable energy (RE) technologies. People are increasingly harnessing wind, solar, geothermal, and biomass (among others) to power their communities and reduce their contribution to the wider global climate change crisis.

\section{Climate Change and the Need for Energy Resilience}

According to author, educator, and leader in the field of community economic development Michael Lewis, the climate change crisis is the preeminent threat to the survival of all living creatures and unless we act immediately, human suffering will continue to increase and we will be "coping with a tapestry of triage" (2017, p. 35). Reliance on fossil fuels must be decreased in order to reduce this threat, but this cannot happen overnight due to an entrenched system that operates on these fuels. Lewis (2017) suggests that a "planned and controlled implosion" (p. 36) of the use of fossil fuels, combined with a ramp-up of renewable energy technologies, will facilitate the transition to a more resilient and climate-friendly system. 
Resilience within the energy sector refers to the ability (of the system) to prepare for and adapt to changing conditions, and withstand and recover rapidly from disruptions (U.S. Department of Energy, 2018). In the past, fossil fuels were considered abundant and readily available, and thus represented a resilient energy system. In recent years, however, the decline in oil and coal reserves (Ecotricity, 2018), coupled with their association with greenhouse gases and the related effect on the global climate, has put this entrenched energy system into question. Valentine (2011) suggests that unless the renewable energy regime can show that it offers a reliable solution to fossil fuels/nuclear power, coupled with carbon sequestration, "the ascendency of renewable energy technologies to global dominance will be slow in materializing (if at all)" (p. 4573). The good news is that the symbiosis between energy security requirements and fossil fuels is beginning to corrode due to lack of availability, affordability, and resilience. Out of this, a new symbiosis between energy security and RE technology is emerging (Valentine, 2011).

The most secure way to minimize risk in disruptions to energy supply is to maximize domestically controllable "common" sources such as wind, solar, and hydropower, thereby allowing people who share them to "roll back the privatization and marketization of their shared resources" (Bollier, 2016). By making the most of these inalienable resources, communities are increasing their energy resilience while gaining participatory control and building social capital. Renewable energy systems are advancing technologically, they are becoming more affordable to implement, and they enhance resilience due to their decentralized nature. Any disruptions to major electrical grids have less impact if communities are using RE in combination with diesel backup (Valentine, 2011).

Community-based renewable energy initiatives are described as "projects where communities (of place or interest) exhibit a high degree of ownership and control, [and are] benefiting collectively from the outcomes" (Seyfang et al., 2013, p. 978). When a community comes together to develop, deliver, and benefit from sustainable energy (Langham, 2018), individuals become empowered and are more likely to become involved in clean energy beyond the bounds of their own homes or businesses. Participating in the energy resilience of the community is an approach to implementing RE technologies that places emphasis on "engagement and empowerment, self-sufficiency and local determination" (Müller, Stämpfli, 
Dold, \& Hammer, 2011). Community-led RE also fosters a transition to $\mathrm{RE}$ generation as part of a wider environmental transformation, because taking action at the local or regional level while seeking to influence macrolevel policies is a step towards "glocalization" (p. 36), or scaling up of local initiatives to influence the lives of more places and people (Lewis, 2017).

Community renewable energy is a sector comprising different organizational forms, and the success of a form in a certain area is dependent on the policy frameworks and types of collective organization present there (Becker, Kunze, \& Vancea, 2017). Some of these include co-operatives, community charities, development trusts, or shares owned by a local community organization that have been given or sold to the community by a commercial project. An example of this would be the donation of one or more wind turbines to the community, such as at Earlsburn wind farm in Scotland (Walker, 2008). Projects may be $100 \%$ community owned, which means they are wholly paid for by community members through a share program or community trust, or they may be developed under a co-ownership arrangement with the private sector, for example community ownership of one turbine in a larger wind farm as previously mentioned (Walker, 2008).

Distinguishing community energy initiatives from other types of $\mathrm{RE}$ projects can be problematic in that community is a contested concept, one "whose nature it is to be open to endless dispute" (Diamond, 2004). Because of the wide range of possible meanings of the word "community," using it in a context such as this can impart a degree of ambiguity. Walker and Devine-Wright (2008) helped to clarify the meaning of a community renewable energy project by using a two-dimensional framework assessing both the process and outcome of the project-namely, who runs the project and who benefits from it both economically and socially. If it falls within the realm of open and participatory as well as local and collective, it can be considered community renewable energy (Walker \& Devine-Wright, 2008).

Figure 1 provides a visual representation of the benefits of community $\mathrm{RE}$ projects and illustrates the overlapping opportunities that the political, environmental, economic, and technological domains provide to the social domain. Several key distinguishing characteristics constitute a community $\mathrm{RE}$ project, including community ownership; wider community benefits (financial, community development, and community building); and active 
engagement of community members (Starfish Initiatives, 2013). As Figure 1 shows, the largest beneficiary of community RE is the community in which the project is implemented.

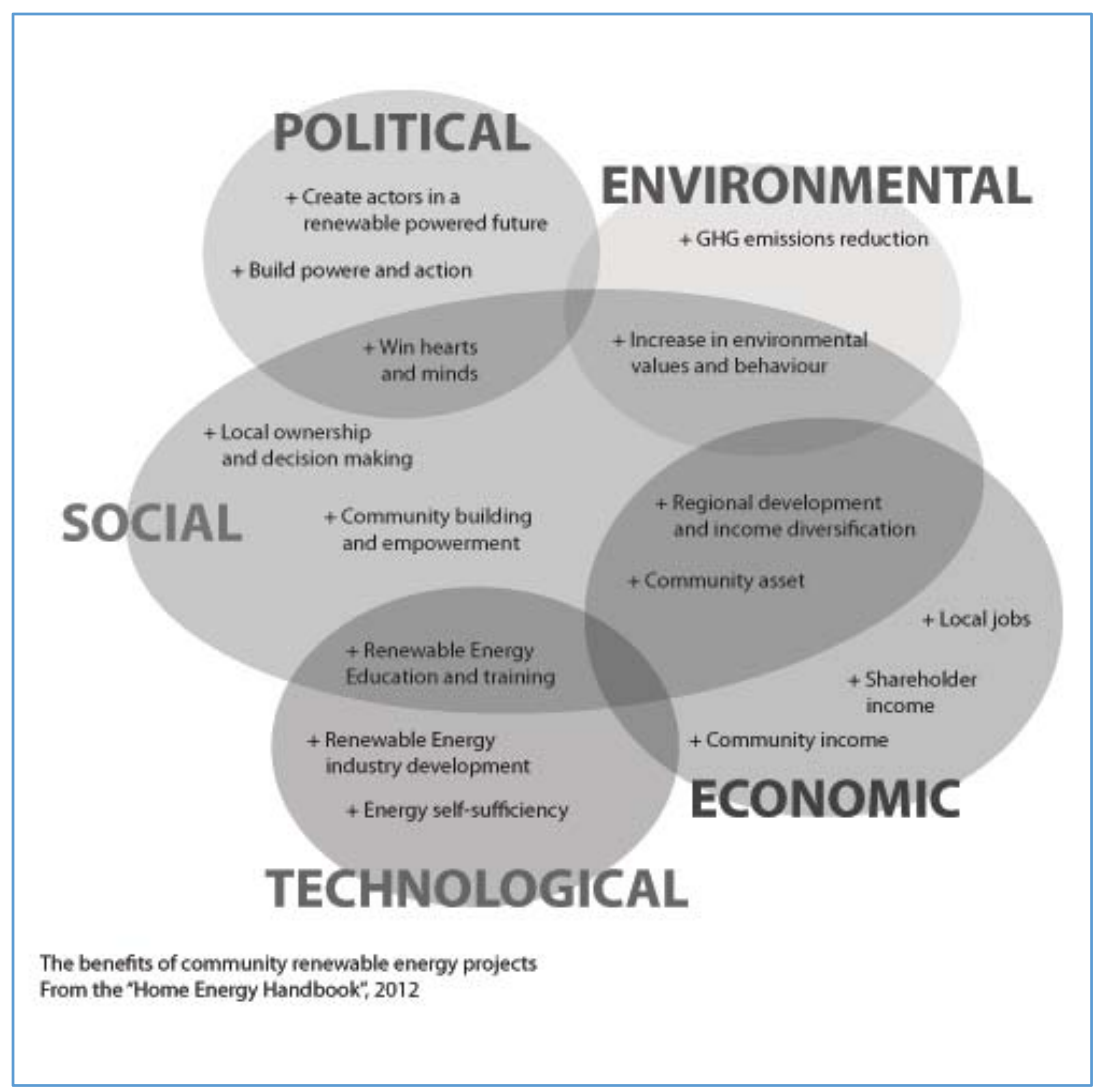

Figure I.The Benefits of Community Renewable Energy Projects.Reprinted from "Community Renewable Energy - Challenges and Opportunities" by Starfish Initiatives, 2013. Retrieved from http://starfish-initiatives.org/community-renewable-energychallenges-opportunities/. 
According to Michael Lewis, co-operative economic democracy and the solidarity economy are key concepts to help transition the world to a new system that values resilience over growth, co-operation over competition, and sufficiency over efficiency, among others (2017). Availability of fossil fuels is dominated by capital that seeks to control their provision, but for $\mathrm{RE}$ the transition is facilitated by decentralized, democratic forms of ownership at the local and regional levels. Wind, sun, water, and geothermal energy are part of our earthly commons and as such can be considered to be inalienable; therefore, community $\mathrm{RE}$ promotes the transition in ways that privatization and marketization cannot. Implementation of community $\mathrm{RE}$ can be considered a form of "commoning" as capitalist markets are tamed and the benefits of shared resources are mutualized (Bollier, 2016). Moreover, grassroots implementation of these technologies is important because engagement at the household and business level increases, thereby increasing uptake of these technologies and accelerating the transition to community RE. Inequality can also be reduced through distribution of economic benefits to a broader population while its citizens become empowered and human capital mobilized (Lewis, 2017). Other benefits of RE implemented with a community approach include increases in local income and regeneration; local approval and planning permission; local control of the project; lower energy costs and reliable supply; ethical and environmental commitment; and load management (Walker, 2008). If the community is engaged in the project, they are more likely to work towards its continued success.

Using the social economy as a lens to view problems as opportunities is one way that $\mathrm{RE}$ initiatives are making an impact in Canadian communities (Loney \& Braun, 2016). In recent years, successes with implementation of RE technologies have been documented in Canada as communities attempt to solve social problems such as poverty and unemployment while increasing their energy security. This approach has been shown to be effective, particularly if implemented within the community, by community members. Loney and Braun (2016) call this the solutions economy and note that it takes an "army of problem solvers" (p. 8) to reverse the poverty that is rampant in many areas of Canada. If prosperity is the antidote to poverty, as Loney and Braun (2016) attest, then the issues that face Canadian communities, for example, can be viewed as opportunities, and problem solvers must look for the "upside to down" (p. 2). Community 
$\mathrm{RE}$ is one way to provide jobs and skills if the projects are implemented with social objectives in mind; not only do these technologies move the community towards energy resilience, they provide jobs and opportunities by empowering the community to solve their own social and environmental problems simultaneously.

\section{The Yukon's Social Economy}

The social economy in the Yukon is unique in that it has been impacted by three factors: the presence of a mixed economy (reliance on wages from labour as well as traditional Indigenous subsistence hunting and fishing), a history of large-scale resource exploitation, and the importance of the state (Southcott \& Walker, 2015). In Indigenous communities, the values of group co-operation and sharing related to subsistence hunting and fishing serve as a "potential source of encouragement for social-economic sector development" (Southcott \& Walker, 2015, p. 17). Conversely, the history of resource development, as well as government presence (the state), results in the absence of a stakeholder culture as well as a culture of dependence, which may negatively affect the development of social economy businesses (Southcott \& Walker, 2015). In the Yukon, each of these three factors play a role in the state of the social economy. The Yukon is comprised mainly of Indigenous and mixed communities, and the Yukon's history of resource exploitation is well known, from the gold rush in the late 1800s to the Faro mine, which at one time was the world's largest open pit lead-zinc mine (Faro Mine Remediation Project, 2016). With regard to importance of the state, one in three people work for some level of government in the Yukon, and the majority of private sector businesses exist to provide products and services to government (Lionais \& Hardy, 2015).

Although there is a strong presence of social economy organizations in the Yukon, most exist to meet the needs that are unmet by the Yukon government and as such there are few involved in trade, finance, and insurance (Lionais \& Hardy, 2015). In other words, the social economy of the Yukon predominately fills a "welfare" role in which funds are moved from the highly paid government and resource sectors to the social economy sector where additional support and financial assistance are required. The Yukon's economy is largely dependent on government and, although the Government of Yukon provides support to several non-profit societies through platforms such as the Community Development Fund (Yukon 
Government, 2018), this atmosphere is not an environment in which cooperatives and other types of social economy businesses have historically thrived.

Although social economy businesses such as co-operatives have not historically been as successful in the Yukon as in other parts of northern Canada, the wider social economy does exist here and includes many businesses, associations, and charitable organizations. There are organizations as well as less-formalized groups with a high level of civic engagement, comprised of people engaging with one another constructively (Quarter et al., 2009), such as (co)Space and YuKonstruct. In the realm of the government-supported social economy sector, there are no shortages of non-profits as over 600 exist (Volunteer Yukon, 2018). Although not as numerous as non-profits, there are community economic development businesses such as the Yukon Arts Centre and the United Way Yukon, and social enterprise businesses such as the Challenge Disability Resource Group, Autism Yukon, and Learning Disabilities Association Yukon, to name a few (Walker, 2012). The social economy in the Yukon is robust, particularly with non-profits.

\section{Social Enterprise Businesses}

One way to implement projects with social objectives while empowering the community is through deliverying community RE projects. Social enterprise businesses provide another way. A social enterprise is a "form of community economic development in which an organization exchanges services and goods in the market as a means to realizing its social objectives or mission" (Quarter et al., 2009, p. 136). Many social enterprise businesses operate within the social economy as non-profits, which exist primarily to meet their social mission, but they also compete alongside conventional businesses and can "go where the private sector and governments cannot" (Loney \& Braun, 2016, p. 6). They comprise many different forms and address various needs within the non-profit sector, but they act as forprofit businesses that use market forces to fulfil their social purpose. Some of these forms include training organizations, subsidiaries of non-profits, or First Nations-owned businesses. Community RE delivery via social enterprise can fall within any of these forms, depending on the specific social mission of the business (Quarter et al., 2009). 
Social enterprises represent an organizational form of community $\mathrm{RE}$ delivery that can be successful because they are economic entities that use market forces and "combine the entrepreneurial savvy of the business sector with the community ethos of the non-profit sector" (Loney \& Braun, 2016, p. 10). They are businesses of the people and for the people and have been a successful tool for community RE delivery, particularly in Indigenous communities in Canada (Loney \& Braun, 2016).

Using social enterprise to deliver community $\mathrm{RE}$ is a relatively new approach as countries begin to adapt how they get their energy in light of the changing climate and its consequences. Fossil fuel reserves are diminishing (Ecotricity, 2018) and alternative energy systems are beginning to gain momentum. In the past, development of $\mathrm{RE}$ through large private enterprise has not been as successful as traditional methods of centralized energy production and distribution; this has been for many reasons, some of which include opposition from local community groups and lack of planning and political support for RE initiatives (van der Horst, 2008). Social enterprises and RE, however, share both social and environmental values - they encourage capacity building, they promote leadership and partnerships, and they increase education. Social enterprises are often started within the community by community members; therefore, they are able to reduce opposition to the projects due to a certain level of trust and networking (Seyfang et al., 2013). The central tenets of community empowerment, committed community members, and environmental stewardship (among others) are also shared by both community renewable energy and social enterprises. Social acceptance is key for successful community RE delivery (Wüstenhagen, Wolsink, \& Bürer, 2007), therefore use of a local non-profit social enterprise to deliver these technologies can engender trust and increase their acceptance and eventual success. Using the social economy (including social enterprise businesses) to deliver RE projects brings the "community" to community renewable energy.

\section{Community Renewable Energy Delivery}

Although two-thirds of Canada's electrical supply now comes from renewable sources such as hydro and wind power (Rabson, 2018), many of the studies documenting the successes and failures of community RE have taken place in the United Kingdom (UK). The UK government is supportive of community $\mathrm{RE}$ and extols its virtues, including its contribution to 
economic distribution, social cohesion, public understanding, and support for RE (Walker, 2008). Seyfang et al. (2013) surveyed 190 community RE organizations in the UK and stated that factors influencing successes and failures of community $\mathrm{RE}$ can be grouped into five levels that correlate with different levels of activity: 1) group, 2) project, 3) community, 4) network, and 5) policy. For successful community RE initiatives, having committed and engaged individuals at the group level can help to maintain momentum and overcome setbacks, and at the project level, the availability of time, resources, skills, and financial support are key. At the community level, the project must meet the residents' needs and engage them as well as foster interpersonal trust; at the network level, supportive partnerships and information sharing are important; and finally, at the policy level, there must be a supportive national policy present (Seyfang et al., 2013).

Understanding the barriers to success is also important to ensure community RE can be delivered successfully. Factors at the five levels introduced above can also bring challenges to a project, including, but not limited to, the following: mismanagement or lack of direction, lack of resources, community mistrust, lack of learning and skills consolidation, and lack of policy support and government funding (Seyfang et al., 2013). Viardot (2013) took a different approach by considering $\mathrm{RE}$ as a new technology and using the Technology Acceptance Model to uncover barriers to successful implementation. Perceived usefulness is an important driver to uptake of new technologies; therefore, renewable energy can be thought to have low usefulness due to its unreliability, whether that unreliability is real or perceived. It can also be considered an unnecessary hassle with a low perceived ease of use and lack of familiarity, and high costs can impede the adoption of RE by communities (Viardot, 2013).

Local participation is seen as a way to increase the legitimacy of decision processes, which in turn can increase the acceptance of community RE initiatives; but these processes must engender trust (Müller et al., 2011). Trust is a "lubricant" for co-operative behaviours and it is an important factor in community RE implementation success because interpersonal and social trust can be enhanced by a community approach. It has an important role in building mutual respect and reciprocity, fostering collaboration, and building social capital (Walker \& Devine-Wright, 2008). In past cases, RE has been implemented by government and private industry with a diversity 
of motives that in some cases have damaged social trust; community $\mathrm{RE}$ implements technology in a way that is consensual and builds "wider societal trust in renewable energy from the bottom up" (Walker, DevineWright, Hunter, High, \& Evans, 2010, p. 2657). Walker et al. (2010) used the case of the Moel Moelogan wind farm in the UK to demonstrate that lack of collaboration, local participation, and consensus resulted in an erosion of trust that proved to be an obstacle to the RE technology's implementation and eventual acceptance.

\section{Energy Generation in the Yukon}

Almost all (94.2\%) of Yukon's electricity is generated in hydroelectric facilities, constitutes 35\% of Yukon's energy consumption, and services all but five Yukon communities (Kishchuk, 2018). This does not include heat or transportation by non-renewable sources such as fossil fuels, which constitutes the consumption of the other $65 \%$ of energy supply. The Yukon is unique with regard to its energy sector, which is due, in part, to the fact that the grid is "islanded" (i.e., not connected to adjacent transmission grids in British Colombia, Alaska, or the Northwest Territories). The implications of this are that all electricity used must be generated here, yet the system cannot be oversized because excess energy would be wasted due to an inability to export, which necessitates a balancing act. Intermittent forms of RE supply such as wind or solar are difficult to integrate into the grid because they cannot guarantee meeting peak demands. This requires capacity redundancy (such as diesel) and drives up the costs of RE in the Yukon (Kishchuk, 2018).

The grid is supported by hydroelectric facilities (Whitehorse, Aishihik, and Mayo) as well as liquefied natural gas (LNG) and diesel generation facilities which are used during periods of peak demand or during hydro disruptions. The Whitehorse hydro plant was built with two turbines in 1958, and two more were added in 1969 and 1985 to support a growing Yukon population and economy. In the summer, the Whitehorse hydro facility can produce 40 megawatts of power, and in the winter it can only produce about 25 megawatts (Yukon Energy, 2018). 


\section{Viability of Community Renewable Energy in the Yukon}

The Yukon climate is primarily Subarctic, characterized by long, cold winters and brief, warm summers, which means there are technical constraints when considering the viability of types of RE here. Off-grid solar systems, which operate efficiently during the summer when daylight can last almost 24 hours, require a system (such as batteries) to store excess energy in the summer, and a backup energy source (such as diesel) will still be required during the darker winter months. Wind energy is viable but its limitations include installation and shipping costs, the requirement to be located near communities to minimize transmission distances, and technical challenges connecting to the existing grid. Large geothermal heating systems are not currently being used, but the potential exists because the southwest corner of the Yukon sits on the North American tectonic plate and most geothermal energy is harvested near tectonic plate boundaries (Northern Vision, 2018). Ground-source heating systems have limited use in the Yukon because permafrost may impede their effectiveness, and thermal imbalances and resultant infrastructure damage due to frost heaving could be encountered (Meyer, Pride, O’Toole, Craven, \& Spencer, 2011). Given that our northern climate presents some specific challenges, hybrid systems that combine the aforementioned RE technologies (i.e., solar in the summer and wind in the winter) may help to increase the viability of site-specific systems. For example, in Alaska, communities are using microgrids to solve their energy needs; these hybrid systems use renewables with diesel backup and route excess electrical energy (or excess electricity) produced by wind turbines to heat electric thermal storage appliances. This allows homes connected to the grid to cut home heating costs by as much as $50 \%$ (Cotsirilos, 2018).

Despite the technical barriers sometimes encountered when RE systems are implemented in the Yukon, innovative solutions are being discovered on a regular basis. The Energy Branch of the territorial Department of Energy, Mines, and Resources provides incentives, support, and RE training (Government of Yukon, 2018). Several of the First Nations have implemented RE, and are continuing to explore solar, wind, geothermal, and biomass technologies as well. The Kluane First Nation has received federal and territorial funding to install three wind turbines in the Kluane Lake area (Byers, 2017), and the Vuntut Gwitchin First Nation is installing a federally funded, yet community-owned, 940 kilowatt hour solar system. 
These projects are but a few examples of how Yukon communities are moving from passive acceptance to active engagement in an attempt to decrease their reliance on diesel fuel and increase their energy security.

Conditions exist in the Yukon, however, that present other barriers to accepting renewable energy technologies. One such barrier may involve difficulty in adopting $\mathrm{RE}$ in small, remote communities where people have neither the expertise nor the familiarity required to install, operate or troubleshoot these types of systems. According to the TAM model introduced earlier, perceived usefulness, reliability, and ease of use can also present barriers in small communities that rely on diesel and have done so for decades. With community-led RE, however, barriers like these are not insurmountable. With the use of trained and enthusiastic people to introduce the technology and incite interest, community groups can begin to implement $\mathrm{RE}$ technologies at the household and business levels, thereby increasing civic engagement and building social capital. Social diffusion can then increase acceptance and understanding of RE and momentum can be gained. With this co-operative approach, trust increases as residents begin to understand the technologies and see the benefits at home, which can in turn foster trust in the larger RE systems and the community groups that implement them. This is happening in several First Nation communities in the Yukon and their success is a portent for other communities. If a commons discourse can be introduced and communities begin to understand that their local changes can have global impacts, there is hope that the Yukon can move towards energy resilience, one community at a time.

\section{Research Methods}

Through review of the available literature to determine success factors for community RE delivery and then linking these factors to social economy business models that can support community RE, this project considered the potential sustainability of community RE in the Yukon. The research was designed to fill the gaps in the literature, and the findings have been applied to a northern model to suggest whether community RE can work in the Yukon, and whether the social enterprise is an appropriate business model to deliver it.

Interviews and document reviews comprised the primary sources of data and were purposefully selected (Creswell, 2003). These methods 
were chosen since a social enterprise has not yet been used to deliver RE projects in Yukon communities. Participants who were considered experts in their fields were interviewed. Participation was solicited directly from experienced and knowledgeable individuals involved in the Yukon's social economy, as well as those involved in RE projects in communities. Six individuals fitting these criteria were interviewed:

Participant 1: A Canadian author and social entrepreneur (male, 3545) who works with Indigenous groups to find solutions to social problems while providing employment and building social capital in communities of various sizes (many of these projects involve renewable energy)

Participant 2: A businessperson (male, 45-55) who has spent 20 years designing solutions to help communities move away from diesel reliance by implementing community renewable energy systems

Participant 3: A consultant (male, 30-40) who works for a non-profit in the Canadian North that connects funding to community groups for various social purposes;

Participant 4: A local Whitehorse engineer (male, 40-50) who has worked within the renewable energy sector for over twenty years and whose primary goal is to build a renewable energy economy in the Yukon and Canada's remote communities;

Participant 5: A Whitehorse energy planner (male, 30-40) who works within the territorial government to assist First Nations groups to plan renewable energy projects in the communities; and

Participant 6: A Canadian university professor and researcher (male, 50-60) who has spent over fifteen years researching the social economy in the North and specifically in the Yukon.

The semi-structured interviews involved questions on topics such as professional background and area of expertise; participant's history with community renewable energy projects; barriers to successful renewable energy delivery encountered; suggestions for overcoming these barriers; opportunities for the Yukon government to help Yukon communities to move away from diesel reliance; participant's level of community involvement in any $\mathrm{RE}$ projects; whether community involvement was a factor in the success/failure of projects; suggestions to finance/subsidize community renewable energy for Yukoners; and advice for companies interested in providing renewable energy to Yukon communities. 
The participants were purposefully selected from a range of backgrounds in order to gather as much relevant information as possible, yet limitations were noted afterwards in that these participants were sampled from similar ethnic and age groups, which could introduce some bias in the data. Although the participants were considered experts in their fields and brought considerable knowledge to the study, introducing variability in the sample (such as interviewing a First Nations RE champion or introducing a female perspective) could have added validity. An interview with a community-based provider or end-user of community RE in the Yukon could also have added credibility. This point of view has potential to provide valuable front-line perspectives on how to increase the chances of RE technology acceptance. It could also provide insight on factors that increase the potential for successful RE delivery in Yukon communities.

\section{Results Overview}

During the interviews and documents review, it became clear that the Yukon is unique with regard to its culture, the role of the state, and technical considerations. A total of five overall categories and their sub-themes were developed and are summarized in Table 1 . Within these categories, other major themes such as capacity, education, ownership and control, and the impact of Indigenous groups on leading the divergence from diesel began to form.

\section{Role of the State}

The "state" refers to any of the three levels of government (federal, territorial, or municipal), but the level with most influence on the social economy and RE initiatives in the Yukon is territorial. Although this was a predetermined theme, the Yukon government's impact on the culture, history, and economy of the Yukon was greater than expected, particularly with regard to how its involvement in the resource industry has shaped our social economy. Some additional prominent themes include funding and the opportunities it creates; the role of policy for including RE and energy efficiency initiatives in government projects; government support for social enterprises and how it can reduce the cost of social assistance; and the notion of risk and its impact on the level of support that the government is willing to provide, given that it is a risk-adverse entity. 
Table I. Overview of Major Research Themes:A Social Enterprise Approach to Using Community Renewable Energy (RE) in the Transition to Energy Resilience

\begin{tabular}{|c|c|}
\hline Theme & Explanation \\
\hline Role of the State & $\begin{array}{l}\text { This theme refers to the influence that government at all } \\
\text { three levels (particularly territorial) has on the culture, his- } \\
\text { tory, and the economy of the Yukon, including the social } \\
\text { economy. }\end{array}$ \\
\hline Community Connection & $\begin{array}{l}\text { This theme highlights the important connection between } \\
\text { the social economy and community RE, and involves the } \\
\text { central tenets of capacity, empowerment, and community } \\
\text { champions. }\end{array}$ \\
\hline Yukon Cultural Influence & $\begin{array}{l}\text { The history and culture of the Yukon both have an impact } \\
\text { on the success of new business ventures here, particularly } \\
\text { social economy businesses. The history of resource de- } \\
\text { pendence, perception, and First Nations ascendancy with } \\
\text { regard to RE systems emerged as dominant themes. }\end{array}$ \\
\hline Technical Considerations & $\begin{array}{l}\text { Almost all (94\%) of the electricity generated in the Yukon } \\
\text { is generated from hydroelectric facilities and supplied to } \\
\text { a grid that is not connected to any other electricity grids. } \\
\text { This "islanded" network combined with the availability } \\
\text { of affordable (and renewable) hydroelectricity introduces } \\
\text { some technical challenges that must be considered when } \\
\text { considering potential RE technology projects. }\end{array}$ \\
\hline Social Enterprise Start-up & $\begin{array}{l}\text { Social enterprise delivery of community RE projects has } \\
\text { been successful in other areas of Canada and the North, } \\
\text { but the unique technical and cultural influences present } \\
\text { here must be considered. This theme arose from discus- } \\
\text { sion of those specific considerations, as well as some } \\
\text { general tips for starting this type of business. }\end{array}$ \\
\hline
\end{tabular}

\section{Community Connection}

As highlighted in the literature review, the parallels between community $\mathrm{RE}$ and the social economy rest largely upon community connection. The central tenets of capacity, empowerment, and committed community members or "champions" were strongly reflected in the research and, unsurprisingly, emerged as the dominant themes. These major themes revealed that some of the most important factors for successful community $\mathrm{RE}$ delivery occur at the community level and involve having committed, engaged, and educated people to champion the technologies and facilitate 
their acceptance because, according to Participant 5, government support to communities "can only take it so far" (personal communication, July 24, 2018). The human resources to manage the business side of $\mathrm{RE}$ projects, as well as people trained to operate and maintain the systems in perpetuity, are deficiencies that are best solved by increasing capacity and education in the communities. Those communities that had a champion, or a proficient and enthusiastic project manager, had the most success in making $\mathrm{RE}$ projects viable. Yukon RE project success stories, namely the Old Crow solar project and the Kluane wind project, were discussed with participants because these communities boasted a project manager that was able to secure funding, help overcome administrative hurdles, and hire the experts needed to get the project started and keep it running towards completion.

Another important theme emerging from the interviews, and that aligns with the existing literature, was that of ownership. According to Participant 2, "community control is key to the success of these projects" (personal communication, July 24, 2018). Control promotes project longevity, which translates to cost savings in the home, engagement and employment in the community, and replicability in the region due to adjacent communities seeing the success or spread of interest (Participant 2, personal communication, July 23, 2018). Project success over time is more likely if the community owns the technology and has had some control throughout the project's life. Community members are motivated to assist in its success because everyone is a stakeholder.

\section{Yukon Cultural Influence}

The Yukon has a long history of resource dependence and state influence. About $23 \%$ of the population $(36,000)$ are citizens of one of fourteen First Nations (Government of Yukon, 2018). This multiculturalism has a distinct influence on the economy, which can present opportunities and also introduce barriers to uptake of new $\mathrm{RE}$ technologies and social enterprise businesses. This category and its strong influence on the research was not predetermined; it emerged from the data with themes such as Indigenous ascendancy, perception, spread of interest, and history.

Indigenous groups have been leading the way with community RE delivery in Canada, with the Yukon being no exception. Participant 6 surmised: "I think there's a history of sharing, of the sharing economy that has existed in [Indigenous] communities and that their entire existence is 
dependent upon sharing and they've translated that into their economic models" (personal communication, July 27, 2018). Yukon First Nations could potentially be ideal stewards of community RE systems due to their strong history of environmental stewardship, combined with the sharing economy and lack of control in a past colonial structure. Renewable energy technologies enable Indigenous communities in Canada to care for their traditional territories by enabling a divergence from diesel while maintaining community control of the revenue generation.

Another example of Indigenous ascendancy is the "Divergence from Diesel" initiative championed by the Gwich'in Council International. With funding from Indigenous and Northern Affairs Canada, Gwich'in Council International is developing a plan to measure the costs related to off-grid diesel generation, including costs arising from greenhouse gas emissions as well as the social costs.

Overall, the data revealed that, while there are some challenges with Yukon's cultural influence on the potential success of community RE projects (such as perception and history), the culture is slowly changing from the resource-driven mentality of the past. According to Participant 6, Whitehorse has some of the highest educational levels of all urban areas in Canada and an "old Yukon" and its stakeholder mentality has been replaced by a newer, more cosmopolitan Yukon (personal communication, July 27, 2018). A 2016 Electricity Values survey conducted by the Yukon Bureau of Statistics, and reported in the Yukon Energy State of Play, revealed that close to two-thirds of Yukoners chose RE as their preferred future energy source (59\%), almost one-third chose energy conservation (31\%), and the remaining respondents chose fossil fuels. Survey respondents were also asked to rank four energy factors-cost, environmental protection, reliability, and social responsibility - in order of importance. Environmental protection was ranked first by almost half (44\%) of respondents, followed by cost at $23 \%$, reliability at $21 \%$, and social responsibility at $8 \%$ (Kishchuk, 2018, p. 20). The culture of this new Yukon prefers their energy to be clean and cost efficient, and this bodes well for the future of community renewable energy. 


\section{Technical Considerations}

The low cost of hydro in the Yukon is due to "legacy electrical generation and transmission infrastructure build to support mine operations" (Kishchuk, 2018, p. 25), the capital costs of which were paid for by the federal government and the Northern Canada Power Commission. Participant 5 sums it up nicely: "they're paid for; we just have to do maintenance on them. We have more power than we need in some ways and there's no market for more" (personal communication, July 24, 2018). Unless the community is not on the grid, such as Old Crow, Beaver Creek, Burwash Landing, Destruction Bay, and Watson Lake, competition with low-cost hydroelectric energy makes larger-scale RE systems difficult to implement. Participant 5 outlined three critical factors for successful RE implementation in the Yukon: 1) funding, 2) high cost of electricity or heat, and 3) invested resources (capacity). Areas that are successfully implementing large-scale RE systems are those that have all three critical factors in place: Old Crow and Burwash Landing have received funding, they have the capacity through their community development corporations, and the cost of diesel in these off-grid communities makes $\mathrm{RE}$ implementation a financially viable option. Participant 2 summarized how to assess the viability of renewable energy in a community: "draw a circle around the community and create an energy balance to determine how the renewable energy offsets diesel costs" (personal communication, July 23, 2018). If the offset is robust, the funding is available, and the community capacity is present, the chances of success increase.

Finally, due to the Yukon's islanded electrical grid, if RE technologies are to be implemented, storage is a compulsory component to each system and can be problematic in cold climates, although technologies are advancing. As subsidized hydroelectricity is the primary source of energy in the Yukon due to its availability and low cost, any supplementary $\mathrm{RE}$ technology within this system must integrate into the grid and help offset peak demands. This means that, if peak demand does not align with peak RE production (sunny and/or windy days), energy storage must be

used for the RE system to offset these demands. Types of energy storage include batteries, compressed air, flywheels, hydrogen cells, and capacitors and, according to research by Yukon Energy, battery storage is the most 
promising for the Yukon (Yukon Energy, 2018). Although technically possible, the storage and other components needed to integrate RE systems into the current grid can present barriers by introducing complexities and raising capital costs.

\section{Social Enterprise Start-up}

Advice with regard to starting a social enterprise business, funding opportunities, and personal fulfilment were emergent themes. Participant 6 stated: "the social enterprise, social economy model is probably the best one for developing renewable energy projects to replace diesel in the Indigenous communities. I think you will find almost universal agreement there" (personal communication, July 27, 2018). This was a positive message, to be sure, but the data revealed that the nuances regarding the type of social enterprise and the type of $\mathrm{RE}$ it will deliver both require examining prior to start up.

Participants expressed some notes of caution about starting a social enterprise business in the Yukon. Due to the technical constraints and the state and cultural influences, the type of RE delivered in the Yukon must be approached with care. Participant 5 provided the following advice: "There's no reason you can't do a business for energy. It's just the economics are very competitive, so with everything, what do you want to accomplish? If it's a social enterprise, will you actually have a net impact by trying to generate electricity?" (personal communication, July 24, 2018). The enterprise must use the talent found in the communities, often blue-collar labourers, and therefore a retrofit or energy efficiency business may be the best option to begin with. There is a need for these types of businesses in the territory, and they would not be competing with existing energy generation facilities. According to Participant 5, "There's much more latitude to create a viable business doing energy efficiency work, especially in the Yukon where the quality of our homes is terrible" (personal communication, July 24, 2018). He suggests looking at the need and creating a social enterprise business to fit within that niche.

With regard to how to start a new social enterprise business, Participant 1 suggests "just do it" (personal communication, July 13, 2018); start small and consider a lean start-up that may eventually help to define a direction. Part of his work is to help people start their social enterprise businesses, 
with a key component being how to involve the communities, or doing work "with" instead of "to." He offers the following sage advice:

Well, for every person that's actually doing social enterprises, there's probably 20 people that are hovering around. I encourage you to start a social enterprise and let it lead you in the direction that your life is meant to go, because there's not nearly enough of us that are actually doing stuff. (Participant 1, personal communication, July 13, 2018)

\section{Discussion: Yukon's Transition to Energy Resilience-A Social Enterprise Approach}

The study was designed to answer the following research question: how can the social enterprise model successfully deliver sustainable RE to Yukon communities? Researching potential delivery of community RE via a social enterprise business in the Yukon uncovered unique opportunities and challenges and led to the development of several factors important for success. These factors include the technical environment in the Yukon and how its constraints may shape a potential community $\mathrm{RE}$ venture, opportunities for government to enable social enterprises through innovative procurement options, the importance of building capacity and empowering $\mathrm{RE}$ champions in the communities, the importance of First Nations community development corporations as a model for social enterprise businesses, and insight on how to start a social enterprise business in the Yukon, given the social economy environment here.

This study found that the social enterprise model can be used to successfully deliver sustainable RE to Yukon communities if the types of projects delivered fit within the unique technical and social constraints found here. Figure 2 depicts the most important factors influencing Yukon social enterprise success, with the arrow pointing towards a successful outcome. These concepts are discussed below. 


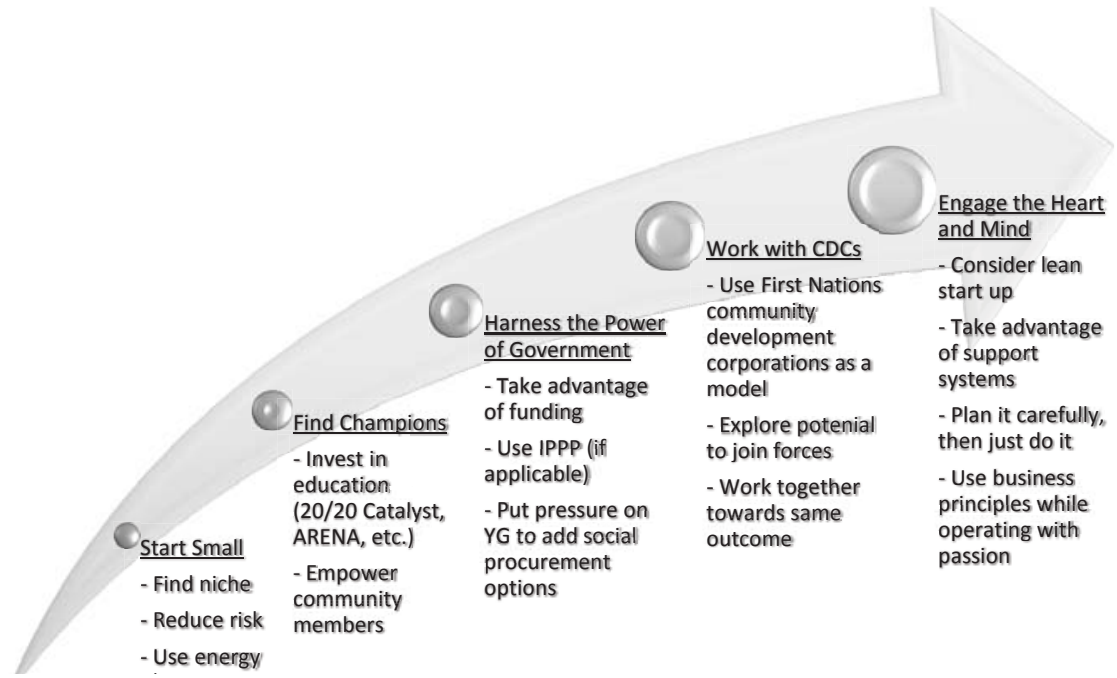

Figure 2. Factors for Successful Transition to Energy Resilience in the Yukon - A Social Enterprise Approach

\section{Start Small}

As noted above, due to the unique constraints present in the Yukon's energy sector, the best way to begin moving towards energy resilience may be incrementally rather than building larger RE systems. Attempting to start a business involving $\mathrm{RE}$ generation or distribution could be challenging due to start-up or initial capital-cost risks, and the availability of low-cost hydroelectricity introduces automatic competition. In order to reduce this risk, provision of a service that helps communities increase their energy conservation and efficiency would be a good first step to reduce diesel consumption. Defourny and Nyssens (2012) noted that those who establish the enterprise often assume the risk until the business becomes viable; therefore, it would initially be borne by the social entrepreneur. In other words, to reduce this risk it would be prudent to find the area that could use improvement in the Yukon, and start at the lowest possible tier of the energy efficiency pyramid to achieve that improvement (see https:// www.nbpower.com/blog/en/posts/2018/october/6-things-you-need-toknow-before-going-solar/). If the business were to grow and expand into larger RE systems later, should there be a need, the risk of that expansion could be assessed at a later date. In this way, the social enterprise would act as a sort of lean start-up. 
To determine the area that could use the most improvement in the Yukon, two salient factors warrant consideration. The first is assessment of the capacity of communities to become involved in the work to "support economic development opportunities that may be a better cultural fit for those communities"(Participant 3, personal communication, July 24, 2018). As noted in the available literature, community ownership and control are crucial to long-term community RE success. In order for the community to become involved in the project, its members must be empowered. This involves creation of jobs, provision of economic benefits, and an increase in training. As Participant 5 discussed, lack of technical and management knowledge can be a barrier in remote northern communities; conversely, a business that uses the existing talent presents an opportunity. He says that in "most of the communities, the skills are trades. You've got a lot of trained carpenters, and a lot of trained boiler mechanics, and so on, who would make a lot of money building good homes" (personal communication, July 24, 2018). Energy retrofits or small-scale renewable systems might be a good place to start.

A second consideration would involve determination of the energy needs of the community. As Participant 2 noted, it is important to perform an energy survey to look for opportunities and define the marketplace (personal communication, July 23, 2018). This is particularly important in the Yukon, given the technical constraints discussed earlier. For most communities, the Government of Yukon has created an energy plan which would be an excellent place to start, considering that a large portion of the energy assessment work has already been done. By understanding the needs of each community, a social enterprise could capitalize on the smallscale improvements that will allow for incremental shifts towards energy resilience.

Application of the five influencing factors, discussed above and visually presented in Figure 3, can be used as an analytical framework and as an initial first step to assessing the probability of success of a community RE project in the Yukon. For example, if a social enterprise were established to provide energy retrofits to Yukon homes, using these five factors might provide insight into the chances of its success or, equally as informative, it might uncover barriers. For example, at the group level, this venture could be successful if a champion were found in the community to tout the 
benefits (financial and otherwise) of the retrofit work, which would help to maintain momentum and overcome setbacks. At the project level, the availability of time, resources, skills, and financial support would provide valuable information about whether to undertake the work or not, and at the community level, the individual costs savings resulting from the project could engage residents to participate in the upgrades. At the network level, supportive partnerships and information sharing are important; if non-governmental organizations, such as the Association of Yukon Communities, are engaged, this could increase chances of success. Finally, at the policy level, there must be a supportive national policy present. Given that one of the current funding pots provided by Government of Canada is for the Clean Energy for Rural and Remote Communities program (Natural Resources Canada, 2018), there is evidence of national support at the policy level. Overall, starting a small niche social enterprise to provide energy retrofits could be a low-risk way to successfully deliver community $\mathrm{RE}$ in Yukon communities.

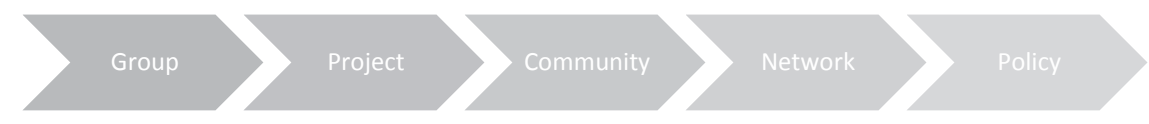

Figure 3. Five Influencing Factors in Community Renewable Energy Project Delivery. Source:Adapted from Seyfang et al. (20I3) "A thousand flowers blooming? An examination of community energy in the UK"

\section{Find Community Champions and Build Capacity}

The social enterprise model can successfully deliver sustainable RE to Yukon communities by ensuring that the community has someone who can champion the technology. Champions add the "sustainable" to successful community RE delivery because their enthusiasm and involvement promotes longevity. The research showed that this is indeed true, as successful RE projects in the Yukon all boast a committed champion. This is so important, in fact, that it is one of the three critical factors listed by Participant 5 for successful RE implementation in the Yukon: 1) funding, 2) high cost of electricity or heat, and 3) invested resources/capacity. If the "invested resources" are not in place, the community is at risk of failing over the long-term because momentum may not be maintained, and "everybody pats each other on the back and they walk away" (Participant 5, personal communication, July 24, 2018). 
Investing in community members through programs such as the northern-focused ARENA training (Arctic Remote Energy Networks Academy) builds capacity and creates champions through empowerment. According to their website, ARENA "provides an opportunity for northern energy champions to gain RE literacy and unique exposure to renewable energy options"(University of Alaska Fairbanks, 2018). Two of the Yukon's biggest RE projects, the Old Crow solar array and the Kluane wind project, are championed by graduates of the ARENA program (Participant 5, personal communication, July 24, 2018). Investments in community empowerment and education is money well spent and pays dividends well into the future. A social enterprise business delivering community RE would be investing in success by ensuring that environmental education is part of its mandate.

\section{Harness the Power of Government}

Given the widespread presence of the state in the Yukon's economy, the Government of Yukon has a role to play in the move towards energy resilience. As this research shows, that role can be a positive one. Opportunities exist for government to advance this transition, including funding, procurement strategies, and administrative support.

One of the most obvious ways that government can help is through funding initiatives. There are currently several budgets available through the Government of Canada (with some delivered by the Government of Yukon) that can be accessed by communities to increase their energy resilience. These include the Green Infrastructure Fund, the Clean Energy for Rural and Remote Communities fund, and the Clean Energy Innovation fund, to name a few (Natural Resources Canada, 2018). The Government of Yukon also provides funding to communities via the Community Development Fund (CDF). The CDF could be accessed by a social enterprise attempting to deliver community $\mathrm{RE}$ projects, as the project criteria aligns with the CDF's values of support of community well-being, job creation, and provision of social, cultural, and economic benefits (Yukon Government, 2018). Although these government funds can be administratively demanding with regard to applications and reporting, they are a good option to finance the social enterprise start-up until it becomes profitable. 
Government has the most power to affect change through its procurement policies. The Government of Canada purchases approximately $\$ 16$ billion on behalf of federal departments and agencies annually (Government of Canada, 2015) and, in 2013/14, the Government of Yukon spent more than $\$ 345$ million on construction, goods, and services (Yukon Government Highways and Public Works, 2014). Clearly, governments have clout with regard to where they spend their dollars, and this is particularly true in the Yukon. The Government of Yukon provides support for First Nation governments, communities and entrepreneurs to generate electricity to sell to a utility through a policy entitled Independent Power Production Policy (IPPP). The objectives of this policy are to support independent power producers to develop local electricity resources that are renewable and/or cleaner than diesel, while respecting the integrity of the existing system (Energy Mines and Resources, 2015). Although some constraints exist, this policy could prove to be a good source of revenue for community $\mathrm{RE}$ projects that involve $\mathrm{RE}$ generation and want to sell that energy back to the state

One other important way that the Yukon government can facilitate community RE project delivery is to remove barriers, or just "get out of the way." During the interview, Participant 1 said, "I think part of the answer lies in how non-profits are treated by government. Generally, we get funding, and ... it's just such a compliance, control oriented, expensive process" (personal communication, July 13, 2018). When asked how government can help Yukon communities move away from diesel reliance, Participant 5 offered: "I think facilitation is the word. The community struggle involves developing proposals and actually securing the money ... right now, nobody is doing that front-end piece very well" (personal communication, July 24, 2018). Reduction of the administrative burden, as well as provision of support for the smaller businesses to access the funding, would be a simple way for the state to advance the transition towards energy resilience.

First Nations Community Development Corporations - A Model for Social Enterprise

Community development corporations (CDC) are economic entities that build community wealth by anchoring capital in the community, often through development of residential and commercial property. Their 
boards are comprised of community members (at least one-third), and they work to enhance community conditions, which builds political power and empowers community members (Community-Wealth org, 2012). In Canada, they were historically started by activists seeking to develop their communities and overcome social and economic problems, and they often provide support for a variety of non-profits, including co-operatives and social enterprises (Quarter et al., 2009).

In the Yukon, most CDCs are for-profit economic development arms of First Nations, and their boards are comprised of First Nations citizens. They use the funding available through land claims settlements, as well as that from the state, in a similar way that a non-profit would access charity or government funding, and they invest the profits back into the community in a variety of ways such as infrastructure development, employment, and RE alternatives. All initiatives contribute to the social and economic well-being of the community while respecting the traditional lifestyle and culture of the people who live there (KCDLP, 2018). The Yukon First Nation CDCs walk through a different funding door than social enterprises, but they tread the same path and their mandates are similar. Complementing the CDCs' mandates, while providing local employment and education, could perhaps even allow a social enterprise to benefit from funding from them. To increase the chances of success while reducing risk, a new social enterprise business should work harmoniously alongside of Yukon First Nations in order to increase the Yukon's energy resilience and divergence from diesel.

\section{Engage the Heart and Mind}

Starting a social enterprise business need not be complicated, particularly if the social entrepreneur takes the unique cultural, historical, and economic factors in the Yukon into account. To increase the chances of success, the Yukon's social economy and its history must be understood and considered; the market and specifics of how, when, and where the business is started must be defined; and the social entrepreneur must ensure that the venture aligns with their own personal values. In other words, the enterprise must be run with business savvy (engage the mind) and passion (follow the heart).

Given that the atmosphere with regard to clean energy in the Yukon is encouraging, a new social enterprise would be advised to reduce risk 
as much as possible while utilizing support systems available to Yukon businesses. In other words, like any for-profit venture, the social enterprise should be operated with intelligence and business acumen. As previously mentioned, starting small, finding a niche market, collaborating with Yukon First Nation CDCs, and taking advantage of available funding would be an excellent place to start. Creation of a business model in which the social value and its associated revenue generation/savings are highlighted is important (Participant 2, personal communication, July 23, 2018), and effort spent researching other social enterprise businesses involved in RE delivery in Canada could provide valuable insight. Finding the balance between preparation and action will allow for intelligent decisions while still doing good work and enabling growth through experience.

Alignment of the social entrepreneur's personal values and interests with the business is key to both initial and continued success of the social enterprise. The owner must be passionate about the environment, the community, and business in order to convince people to invest their money and provide support to the enterprise. If passion and heart are missing, it can eventually manifest potential future failures because, given the choice, communities will choose to support a business that cares. In answering the research question "how can the social enterprise model successfully deliver sustainable renewable energy to Yukon communities?" the social enterprise business owner's passion and heart is what will add the "success" to the equation. If the social enterprise is operated with the mind and led with the heart, it will have the best chance of facilitating the Yukon's divergence from diesel.

\section{Access to Funding as a Critical Factor}

A critical factor required for successful operation of a social enterprise business is the availability of funding, particularly during the start-up phase. Financial risk is inherent when starting a social enterprise; until the business begins generating revenue that can be invested back into the operation of the business as well as towards its social mission, it relies largely upon outside support. This risk necessitated a sub-question: what funding opportunities need to exist to support the social enterprise model? Although funding has been mentioned throughout this article, this section presents several interesting opportunities that emerged during the research. 


\section{Government Financial Support}

In Canada, several federal and provincial/territorial funds could be used to support a social enterprise start-up in the Yukon, but locating these funds and assessing their fit can be a challenge in itself. At the Clean Tech conference held in Whitehorse in March 2018, the Government of Canada presented a tool called the "Innovation Canada Tool" to help businesses and communities locate potential government funding opportunities (https://www.canada.ca/en/services/science/innovation/funding.html). Another potentially valuable website is Funding Portal, which helps match funding with non-profits according to their size, sector, and needs (https:// ca.fundingportal.com/).

\section{Support from Yukon First Nations Community Development Corporations}

Due to their experience and mandate to contribute to the well-being of their communities, how Yukon First Nations community development corporations operate can provide valuable information for a business attempting to navigate the culture and economy in the Yukon. In addition to this insight, they may also be in a position to contribute funding to a social enterprise, particularly if it is a good fit with their current and future goals. These for-profit Yukon First Nation CDCs are well-known for their business savvy and connections, and according to Quarter et al. (2009), CDCs historically have been a support system for related social enterprises and other non-profit organizations.

\section{Impact Investors}

An interesting funding concept that arose through this research involved the utilization of "impact investments" to fund a social enterprise business. Impact investing, a type of funding that falls under the umbrella of socially responsible investing, is defined as "investments intended to create positive impacts beyond financial returns" (Harji, 2013, p. 11). It is differentiated from traditional investments through intention (both investor and investee) and impact measurement, or how the stated intentions translate into social impact. On the supply side, impact investors may include high networth individuals, foundations, Indigenous finance institutions, financial institutions, pension funds, and government. Other related supply-side groups include Community Futures Development Corporations and 
Community Economic Development Investment Funds (Harji, 2013). Social enterprises that take advantage of this type of funding receive both financial and social outcomes.

\section{EmPower the Yukon - An Implementation Framework}

In summary, starting small, finding champions, harnessing the power of government, working with First Nations community development corporations, and engaging the heart and mind may be the best path to starting a successful social enterprise in the Yukon, given the unique constraints present here. However, this path is not linear, as initially proposed. When delivering community RE (or energy solutions) through a social enterprise, each step is equally important. One factor does not have

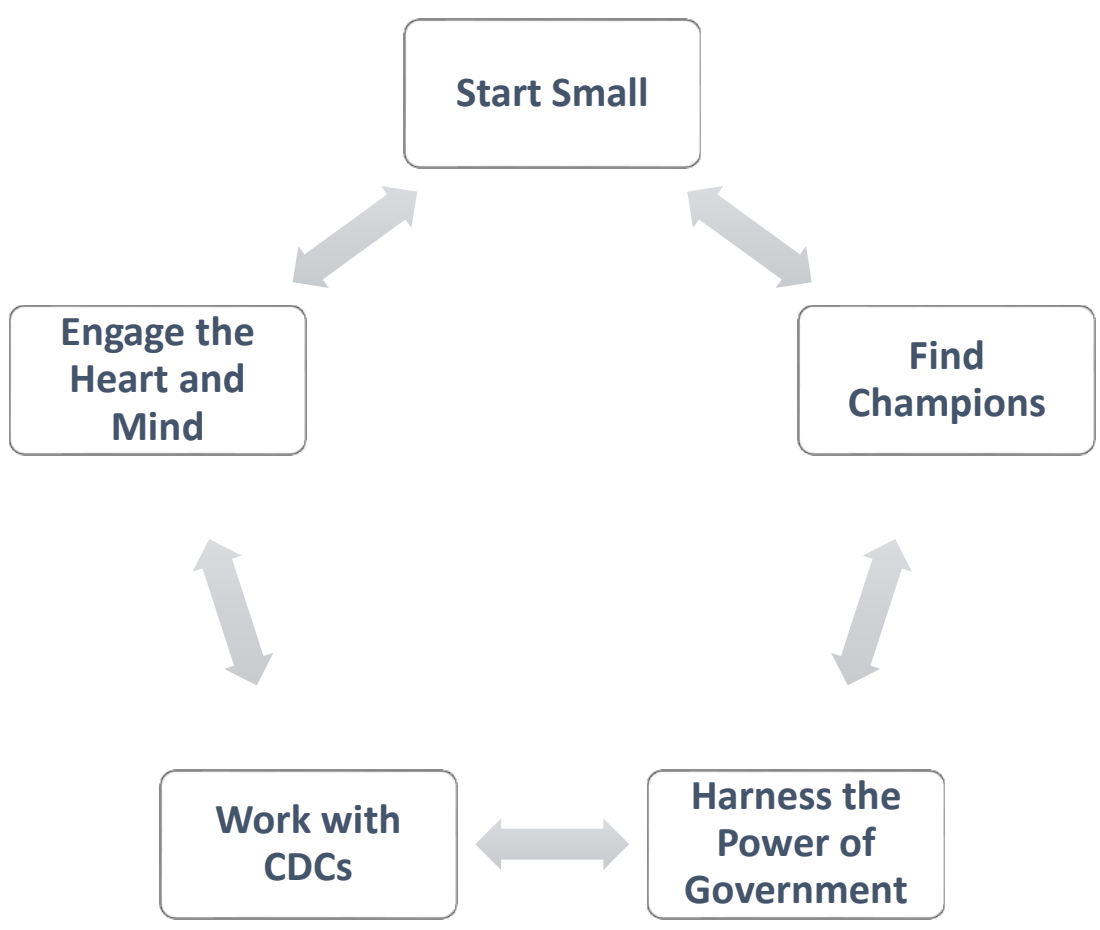

Figure 4. EmPower the Yukon - Implementation Framework 
to occur before the others, hence a non-directional cycle is used to depict the framework, as shown in Figure 4.

One example of how this implementation framework could be used is applying each factor to a potential social enterprise delivering energy home energy retrofits in Yukon communities. The social entrepreneur could first perform an assessment of the energy needs of the community by talking to the municipality as well as the First Nation. Has an energy plan already been produced by the Government of Yukon? Does the First Nation have a community development corporation and, if so, are they currently delivering RE options? Working within the existing RE system (if any exists) and with the First Nation would be key to success, as competition at this phase could introduce risk. Once this assessment has been completed, the entrepreneur should then determine what type of service to offer the community-small-scale renewable energy installations, or energy efficiency retrofits, or both. Either way, the services should be low-cost and easily implementable to start, in an effort to reduce risk and keep the business at a small scale. Deciding what services to provide (technical or training or both) would be a key consideration, as the entrepreneur would want to feel passionate about those services in order to increase the chances of long-term success.

Talking to community members would be an important step to finding a champion and gauging interest in the services. It is at this point that the entrepreneur could assess community amenability to the technology as well as determine how to engage the community members and provide employment. As previously discussed, empowerment is a key factor for successful implementation and ongoing care and maintenance of these systems, so the capacity and interest must exist or be generated through champions and training.

Finally, once the services have been determined and the community has been consulted and is interested (and available) in becoming involved, funding options can be sought. This can happen concurrently to the above processes, particularly when consulting with the Yukon government and the First Nation, but once viability of the business has been determined, concerted efforts can be applied to sourcing financial support. It is at this point that engaging the heart and mind will have the greatest impact, as displaying passion for the proposed business venture, while executing 
funding requests professionally and with business acumen, will produce the greatest success and help to reduce the risk to the entrepreneur.

Application of this implementation framework will empower Yukoners to join forces in the divergence from diesel, thereby increasing the social enterprise's chances of success. It is for this reason the framework is entitled "EmPower the Yukon," as it operates within the Yukon's current energy (power) network while engaging Yukoners to become involved in the transition towards energy resilience.

\section{Conclusion: Move Towards Energy Resilience, One Step at a Time}

While attempting to answer the question how the social enterprise model can successfully deliver sustainable RE to Yukon communities, the research uncovered themes that took the study in surprising directions. After an assessment of the Yukon's cultural, historical, and technical environment, the study found that social enterprise delivery of RE technologies may not be the best place to start the transition to energy resilience. Energy resilience can be realized through many different initiatives, including energy conservation, energy efficiency, and RE systems, but for a social enterprise business in the Yukon, RE systems may be the riskiest place to start. Energy conservation and efficiency may not be as appealing as large-scale RE systems, but the incremental changes associated with these initiatives can be the simplest way to assist in this transition, with the lowest risk to the social entrepreneur. A good example of a social enterprise business that could take all of these factors into account is one delivering home energy retrofits to aging homes in the communities. This type of business would employ local contractors, would build capacity through training, would help communities use less diesel fuel due to increased building envelope efficiencies, and could be well-positioned to receive funding from the Government of Yukon and Yukon First Nation community development corporations. Further research and market analysis would be required, but a lean start-up providing small home efficiencies would be a low-risk way to break into the market.

Although implementation of energy conservation and efficiency measures do not constitute RE and hence do not technically fall within the realm of community $\mathrm{RE}$, this research has shown that community involvement must remain a focal point of the social enterprise. Regardless of whether the transition to energy resilience is through RE systems or 
smaller-scale efficiency measures, community empowerment is fundamental to the success of the social enterprise.

"It's not about big systems, it's baby steps" (Participant 5, personal communication, July 24,2018). The social enterprise model can successfully deliver sustainable RE to Yukon communities by starting small and empowering Yukoners to conserve energy through home, business, and transportation efficiencies; in other words, through application of the "EmPower the Yukon" implementation framework. While experience and growth could eventually lead to delivery of community RE projects, particularly if the social enterprise is working in partnership with Yukon First Nation community development corporations, the biggest impact with the least amount of complexity, cost, and risk lies with smaller changes that provide employment and solve local issues.

\section{References}

A Northern Vision. (2016). A northern vision: Renewable energy inventory. http://www.anorthernvision.ca/inventory

Anderson, C. (2010). Presenting and evaluating qualitative research. American Journal of Pharmaceutical Education, 74(8), 141.

Becker, S., Kunze, C., \& Vancea, M. (2017). Community energy and social entrepreneurship: Addressing purpose, organisation and embeddedness of renewable energy projects. Journal of Cleaner Production, 147(20), 25-36. https://doi.org/10.1016/j.jclepro.2017.01.048

Blank, S. (2013, May 1). Why the lean start-up changes everything. Harvard Business Review. https://hbr.org/2013/05/why-the-lean-start-up-changes-everything

Bollier, D. (2016). Commoning as a transformative social paradigm. The Next System Project.

Byers, A. (2017, October 31). Kluane Lake wind project to go ahead, with investment from Ottawa. CBC. http://www.cbc.ca/news/canada/north/ kluane-lake-wind-project-funding-1.4380814

Charmaz, K. (2006). Constructing grounded theory: A practical guide through qualitative analysis. Sage Publications.

City of Victoria. (2018). Social enterprise and social procurement task force. https://www.victoria.ca/EN/main/city/mayor-council-committees/taskforces/social-enterprise-and-social-procurement-task-force.html 
Community-Wealth org. (2012, June 21). Community development corporations (CDCs). https://community-wealth.org/strategies/panel/cdcs/index.html

Coraggio, J., Eynaud, P., Ferrarini, A., de França Filho, G.C., Gaiger, L.I., Hillenkamp, I., ... Sadik, Y. (2015). The theory of social enterprise and pluralism. In J.L. Laville, D.R. Young, P. Eynaud (Eds.), Civil society, the third sector and social enterprise: Governance and democracy (pp. 234-249). Routledge.

Corbin, J., \& Strauss, A. (2015). Basics of qualitative research. Sage Publications.

Cotsirilos,T.(2018). InKongiganak,groundbreakingmicrogrid cuts heating costs in half. Kuyuk. Public Media for Alaska's Yukon-Kuskokwim Delta http://kyuk. org/post/kongiganak-groundbreaking-microgrid-cuts-heating-costs-half

Creswell, J. W. (2002). Educational research: Planning, conducting, and evaluating quantitative: Prentice Hall Upper Saddle River.

Creswell,J.W. (2003). Research design: Qualitative, quantitative, and mixed methods approaches ( $2^{\text {nd }}$ ed.). Sage Publications.

Creswell, J.W., \& Miller, D.L. (2000). Determining validity in qualitative inquiry. Theory into practice, 39(3), 124-130.

Davidson, D. (2018). Climate change. The Canadian Encyclopedia. http://www. thecanadianencyclopedia.ca/en/article/climate-change/

Defourny, J., \& Nyssens, M. (2012). The EMES approach of social enterprise in a comparative perspective. https://emes.net/publications/working-papers/ the-emes-approach-of-social-enterprise-in-a-comparative-perspective/

Diamond, M. (2004). Community economic development: A reflection on community, power and the law. J. Small E Emerging Bus. L., 8, 151.

Ecotricity. (2018). The end of fossil fuels. Ecotricity. https://www.ecotricity.co.uk/ our-green-energy/energy-independence/the-end-of-fossil-fuels

Energy Mines and Resources. (2015). Independent power production policy. http:// www.energy.gov.yk.ca/independent power production.html

Faro Mine Remediation Project. (2016). Remediating Faro Mine in the Yukon. https://www.aadnc-aandc.gc.ca/eng/1480019546952/1480019612738

Funding Portal. (2012, December 17). Over 1,100 funds available for Canadian non-profit sector.Funds News. https://fundingportal.com/blog/ over-1100-funds-available-for-canadian-non-profit-sector/

Given, L. M., \& Saumure, K. (2008). The Sage encyclopedia of qualitative research methods (L. M. Given Ed. Vols. 1 \& 2). Sage Publications. 
Government of Canada. (2015, 2015-01-21). The procurement process. https:// buyandsell.gc.ca/for-businesses/selling-to-the-government-of-canada/ the-procurement-process

Government of Yukon. (2018). Aboriginal facts and maps - Aboriginal relations. http://www.eco.gov.yk.ca/aboriginalrelations/maps.html

Government of Yukon. (2018). Energy. Energy, Mines and Resources. http:// www.energy.gov.yk.cal

Gwich'in Council International. (2017). Diverging from diesel: Technical report. https://gwichincouncil.com/sites/default/files/Diverging\%20from\%20 Diesel\%20-\%20Technical\%20Report FINAL.pdf

Haggerty, K. D. (2008). The Sage encyclopedia of qualitative research methods (L. M. Given Ed. Vols. 1 \& 2). Sage Publications.

Harji, K. R., Joanna; Best, Hilary; Jeyaloganathan, Mathu. (2013). State of the nation: Impact investing in Canada. http://www.marsdd.com/wp-content/ uploads/2014/09/Impact-Investing-in-Canada-State-of-the-Nation-2014EN.pdf

Hennessey, R. (2018 April 12). What's an energy plan? [Powerpoint presentation] Association of Yukon Communities AGM. On file with author.

Hinzman, L. D., Bettez, N. D., Bolton, W. R., Chapin, F. S., Dyurgerov, M. B., Fastie, C. L., ... Yoshikawa, K. (2005). Evidence and implications of recent climate change in northern Alaska and other Arctic regions. Climatic change, 72(3), 251-298. https://doi.org/10.1007/s10584-005-5352-2

Innovation Canada. (2018). Innovation Canada. https://www.ic.gc.ca/app/scr/ innovation?lang $=$ eng

Johnston, I. (2017, March 30). Plunging price of renewable energy makes end of fossil fuels inevitable, says report. http://www.independent.co.uk/ environment/renewable-energy-transition-from-fossil-fuels-inevitablecanada-clean-energy-a7658891.html

KCDLP. (2018). Kluane community development limited partnership. http:// kluanekcdc.ca

Kishchuk,P.(2018).Yukonenergystate ofplay.http://c7ligl-d8ygafd6hzakmboc522c. remoteaccess.gov.yk.ca

Langham, E. (2018). Communities are taking renewable power into their own hands. The Conversation. http://theconversation.com/ communities-are-taking-renewable-power-into-their-own-hands-42480

Lewis, M. T. (2017, April 18). Navigating system transition in a volatile century. https://thenextsystem.org/navigating-system-transition-volatile-century 
Lionais, D., \& Hardy, K. (2015). Cooperatives and the Social Economy of the Yukon. In C.Southcott (Ed.), Northern Communities Working Together: The Social Economy of Canada's North (pp. 169-189). University of Toronto Press.

Loney, S., \& Braun, W. (2016). An army of problem solvers. McNally Robinson.

Meyer, J., Pride, D., O’Toole, J., Craven, C., \& Spencer, V. (2011). Ground source heat pumps in cold climates. http://www.uaf.edu/files/acep/Ground-SourceHeat-Pumps-in-Cold-Climates.pdf

Müller, M. O., Stämpfli, A., Dold, U., \& Hammer, T. (2011). Energy autarky: A conceptual framework for sustainable regional development. Energy Policy, 39(10), 5800-5810.

Natural Resources Canada. (2018, December 27) Clean energy for rural and remote communities: Capacity building stream. Natural Resources Canada. https://www.nrcan.gc.ca/energy/science/programs-funding/20477

Natural Resources Canada. (2018, June 1). Clean energy innovation. Natural Resources Canada. https://www.nrcan.gc.ca/energy/funding/icg/18876

Northern Vision. (2018). A northern vision: A stronger north and a better Canada. http://www.anorthernvision.ca/

Office of the Auditor General of Canada. (2017, December 5). Climate change in Yukon. http://www.oag-bvg.gc.ca/internet/English/yuk 201712 e 42706.html

OnlineCollege.org. (2012, June 26). The 10 greatest social entrepreneurs of all time. Online college search. Your accredited online degree directory. http://www. onlinecollege.org/2012/06/26/the-10-greatest-social-entrepreneurs-all-time/

Quarter,J., Mook, L., \& Armstrong, A. (2009). Understanding the social economy: A Canadian perspective. University of Toronto Press.

Rabson, M. (2018). Two-thirds of Canada's electricity now comes from renewable energy. Toronto Star. https://www.thestar.com/news/canada/2017/05/02/ two-thirds-of-canadas-electricity-now-comes-from-renewable-energy.html

Saldaña, J. (2015). The coding manual for qualitative researchers. Sage Publications.

Saunders, M., Lewis, P., \& Thornhill, A. (2012). Research methods for business students. Pearson.

Seyfang, G., Park, J. J., \& Smith, A. (2013). A thousand flowers blooming? An examination of community energy in the UK. Energy Policy, 61, 977-989. https://doi.org/10.1016/j.enpol.2013.06.030

Southcott, C., \& Walker, V. (2015). A portrait of the social economy in northern

Canada. Northern communities working together: The social economy of Canada's north, 35(2), 142-164. 
Starfish Initiatives. (2013, March 6). Community renewable energ. Challenges \& Opportunities. Starfish Initiatives. https://starfish-initiatives.org/ community-renewable-energy-challenges-opportunities/

Tobin, C. (2018, March 15). Entrepreneur, innovators to receive a new hub. Whitehorse Star. https://www.whitehorsestar.com/News/ entrepreneur-innovators-to-receive-a-new-hub

TREC. (2018). Renewable energy E social finance. http://www.trec.on.ca/

U.S. Department of Energy. (2018). SNLResilienceApril29.pdf. https://www. energy.gov/sites/prod/files/2015/01/f19/SNLResilienceApri129.pdf

University of Alaska Fairbanks. (2018). ARENA. http://arena.alaska.edu/

Valentine, S. V. (2011). Emerging symbiosis: Renewable energy and energy security. Renewable and sustainable energy reviews, 15(9), 4572-4578.

Van der Horst, D. (2008). Social enterprise and renewable energy: emerging initiatives and communities of practice. Social Enterprise Journal, 4(3), 171-185.

Viardot, E. (2013). The role of cooperatives in overcoming the barriers to adoption of renewable energy. Energy Policy, 63, 756-764.

Volunteer Yukon. (2018). Non profits.http://www.volunteeryukon.ca/non-profits/

Walker, G. (2008). What are the barriers and incentives for community-owned means of energy production and use? Energy Policy, 36(12), 4401-4405. https://doi.org/10.1016/j.enpol.2008.09.032

Walker, G., \& Devine-Wright, P. (2008). Community renewable energy: What should it mean? Energy Policy, 36(2), 497-500.

Walker, G., Devine-Wright, P., Hunter, S., High,H., \& Evans, B. (2010). Trust and community: Exploring the meanings, contexts and dynamics of community renewable energy. Energy Policy, 38(6), 2655-2663.

Walker, V. (2012, March 20, 2012). Social economy research network of northern Canada: Northern social economy organizations. http://yukonresearch. yukoncollege.yk.ca/sern/resources/organizations

World Wildlife Federation. (2018). Climate change in the Arctic. https://arcticwwf. org/work/climate/

Wüstenhagen, R., Wolsink, M., \& Bürer, M. J. (2007). Social acceptance of renewable energy innovation: An introduction to the concept. Energy Policy, 35(5), 2683-2691. https://doi.org/10.1016/j.enpol.2006.12.001

Yukon Energy. (2018). Energy storage. Yukon energy. https://yukonenergy.ca/ energy-in-yukon/projects-facilities/energy-storage

Yukon Energy. (2018). Whitehorse Hydro Plant. https://yukonenergy.ca/ energy-in-yukon/projects-facilities/whitehorse-hydro-plant 
Yukon First Nations Chamber of Commerce. (2018). Yukon First Nations Chamber of Commerce (YFNCC). https://yfncc.ca/

Yukon Government. (2018). Apply for community project and event funding. https://yukon.ca/en/doing-business/funding-and-support-business/ apply-funding-community-projects-and-events

Yukon Government. (2018). Applying for community project and event funding. https://yukon.ca/en/doing-business/funding-and-support-business/ apply-funding-community-projects-and-events

Yukon Government Highways and Public Works. (2014). Procurement Support Centre annual report 2013/14. http://www.hpw.gov.yk.ca/csb/procurementannual-reports.html

\section{Author}

Karen Furlong recently received an MBA in community economic development from Cape Breton University and is an environmental engineer and project management professional, working with the Government of Yukon's Infrastructure Development Branch; she has lived in the Yukon for over twenty-five years. The views and opinions expressed in this article are those of the author and do not necessarily reflect those of the Government of Yukon. 